936 NORMAL MICROTUBULE (MT) ASSEMBLY BY CHEDIAK-HIGASHI 936 Smith \& B.R. B. Brinkley. $\frac{\text { Bnderson }}{\text { Baylor College }} \frac{\text { B. Hughes, }}{\text { of Medicine, }}$ ouston, TX \& Michigan State University, E. Lansing, MI. A new indirect immunofluorescent technique was employed in studies of a 1 y/o $\mathrm{M}$ with CHS to delineate possible functional relationships between assemblage of MTs \& PMN motility, morphology \& surface distributions of adhesion or lectin binding sites. $\mathrm{CH}$ PMNs exposed to gradients of $\mathrm{FMLP}$ demonstrated diminished orientation/migration ( $p<.001)$ but normal numbers of MT/PMNs [34+5 (CH), 36+7 (control)] \& normal MT lengths - [CHS; 6.9+2.0 um (PBS) $\rightarrow 10.1+3 \mu \mathrm{m}$ (fMLP) vs control: $7.1+2$ um (PBS) $\stackrel{10.9+3.1}{\rightarrow} 10$. $\mu \mathrm{m}$ (fMLP)]. MTs of CH \& normal PMNs were equally susceptible to depolymerization by colchicine ( $\mu M)$ \& their reassemblage following fMLP stimuli was normal. Shape change by CH PMNs stimulated in suspension with FMLP $(2 \mathrm{nM}, 5 \mathrm{~min})$ was diminished [mean $\%$ bipolar + uropod forms $=30 \pm 7$ (CHS), $92+6$ (controls), $p<.001]$. Colchicine ( $\mu M$ ) promoted significantly less bipolar shape change of $\mathrm{CH}$ PMNs $(10+6 \%)$ as compared to normal PMNs $(55 \pm 10 \%)(p<.001)$. Conditions promoting a redistribution of surface binding sites for albumin coated latex beads (ACLB) to the cell uropod in normal PMNS [colchicine ( $\mu M$ M) or $F M L P(0.1 \mathrm{nM}, 10 \mathrm{nM})$ ] failed to redistribute (cap) ACLB binding sites of $\mathrm{CH}$ PMNs. In contrast, $\mathrm{CH}$ PMNs demonstrated enhanced spontaneous concanaval in A capping $[55 \pm 7 \%(\mathrm{CH}), 8+6 \%$ (control), $\mathrm{P}<.001]$ or capping following colchicine ( $\mu M$ ) preincubation [ $84+11 \%(\mathrm{CH}), 61+10 \%$ (control)]. Thus, abnormalities of PMN mobility, shape change \& surface distributions of lectin or ACLB binding sites mediated by chemotactic factors are unrelated to pathologic MT assembly.

937 antibOdy (ab) TO THE CAPSUlar POLYSACChaRIDE (PRP) OF 937 HAEMOPHILUS INFLUENZAE B IN 2 TO 6-MO-OLD INFANTS VACCINATED WITH PRP OLIGOSACCHARIDES CONJUGATED TO THE chero, Univ RoTEIN CRM 197. Porter W. Anderson, Michael E. PichiA r r Univ Rochester, Dept. Peds, Roch NY (Spon. David H. Smith) jugated by reductive amination to CRM197, a non-toxic mutant protein of diphtheria toxin. This conjugate, Dcr-vs-1, was previously reported to elicit memory-type Ab responses to PRP in children 12-30 mo of age. In the present study 25-4g doses were given to healthy infants at ages 2,4 , and 6 mo along with conventional DTP vaccine, in a separate site. There were no adverse reactions. Sera were taken before each injection and 1 mo after the third. The sequence is complete for 4 subjects. Anti-PRP Ab titers were determined by radioantigen binding:

\begin{tabular}{|c|c|c|c|c|}
\hline \multirow[b]{2}{*}{$\frac{\text { Subje }}{K G}$} & \multicolumn{4}{|c|}{ Anti-PRP Ab, $\mu \mathrm{g} / \mathrm{ml}$, at age } \\
\hline & $\frac{2 \mathrm{mo}}{0.13}$ & $\frac{4 \mathrm{mo}}{0.056}$ & $\frac{6 \mathrm{mo}}{1.0}$ & $\frac{7 \mathrm{mo}}{33}$ \\
\hline $\mathrm{JH}$ & $<0.020$ & $<0.020$ & 1.2 & 4.2 \\
\hline MM & $<0.020$ & $<0.020$ & 0.062 & 1.5 \\
\hline EC & 0.41 & 0.092 & 0.020 & $<0.020$ \\
\hline
\end{tabular}

Thus no rises were seen after the $1^{\circ}$. There were distinct rises after the $2^{\circ}$ and even larger rises after the $3^{\circ}$ in 3 subjects. Subject EC, who had no detectable response, also had the highes pre-vaccination level (presumably maternal $\mathrm{Ab}$ ). Additional infants and the Ig class specificity and bactericidal activity of the antibodies are being studied. The approach seems promising for prevention of $H$. influenzae $b$ infection in the age range of

AUTOIMMUNE PROFILE OF LYMPHOCYTE SUBPOPULATIONS IN

938 AN ADOLESCENT WITH HISTOPLASMA CAPSULATUM (HC) Rebecca J. Turner, Kay Edmonds, Mary Ellien Kleinhenz, Steven $\underline{\mathrm{W}}$.

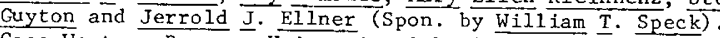
Case Western Reserve University School of Medic ine, University Hospitals of Cleveland, Departments of Pediatrics, Medicine,
and Surgery, Cleveland, Ohio.

MF following $\mathrm{HC}$ infection is regarded as a hyperimmune phenomenon. Circulating lymphocyte subpopulations and lymphocyte blastogenesis were studied before (pre-Rx) and two months after surgery (post-Rx) to remove a medlastinal mass in a $14 \mathrm{y} .0$. male with HCMF. Pre-Rx, the $\mathrm{OKT}_{4} / \mathrm{KKT}_{8}$ ratio was 4.8 (normal $<2.5$ ) and decreased to 2.8 post-Rx mainly due to an increase in $0_{4 T_{8}}$ bearing lymphocytes from $12 \%$ to $19 \%$ (normal 12-24\%). Immunoglobul in-bearing cells also increased post-Rx from $15 \%$ to $27 \%$ (normal 5-17\%). OKT 3 reactive cells were unchanged. Strepto(normal $5-17 \%)$. OKr 3 reactive cells were unchanged. Strepto-
kinase-Streptodornase (SK-SD) failed to induce blastogenesis in peripheral blood mononuclear cells (PBMC) pre-Rx. Depletion of adherent cells resulted in a positive response (stimulation index 5.6). SK-SD and HC mediated blastogenesis were observed in PBMC post-Rx (S.I. 8.1 and 4.5 respectively). Absent blastogenic responses in this form of $\mathrm{HC}$ infection appear to result from suppression by adherent cells. The pattern of circulating lymphocyte subpopulations noted pre-Rx is similar to classical autoimmune diseases supporting the hypothesis that the development of MF after HC infection is immune-mediated.
PROSTAGLANDIR SYNTHESIS BY RABBIT CALVEOLAR MACR.JW:939 GES MEDIATED BY THE ALTERNATIVE COETLENENT PATHW: ACTIVATION. Carlos M. Arrovave, Wei Hsueh, and pith L. Jordan. Northwestern University, Children's Memorial Hospila? Prostaglandin (PG) synthesis by rabbit alveolar macrophiges ( 40 ) was reported to be stimulated by heterologous, homologous and, autologous sera. In the present study we stimulated alveolat ip prelabelled with ${ }^{4}$ C-arachidonic acid with variuos serun prevarations, complement proteins and quantitated their PG release by thin Jayer chromatography. Our expezinents showed that: 1) trypsinized rabbit serum(RS), RS activated with aggregated igG and zymosan, stimulated $P G$ release by $\mathbb{N} \phi S$. 2) Activation of $R S$ with zymosan was more efficient stimulating PG synthesis then RS acti vated with aggregated IgG. 3) When $C 4$ deficient guined pis serim was used, it was clear that activation of the alternative vathway of complement (APC) independent of the classical pathwar, stimulated PG release. 4) We were able to abolish the stinitutory effect of serum and activated $C 3$ (but not zymosan) by blncking the $M \varnothing C 3 b$ receptor ( $33 b R$ ) with anti-C3bR preincubation. Thus we concluded that activation of the alternative pathway of complement plays an important role in PG synthesis by alvenlar macrophages.
$940 \frac{\text { T-CELL INDEPENDENT HUMAN PNEUMOCOCCAL POLYSACCHARIDE }}{\text { ANTIBODY SYNTHEST }}$ Ayoub, Department of Pediatrics, University of Florida College of Medicine, Gainesville.

Antibody responses to Pneumococcal Polysaccharide type 3 ( $P n A b)$ are independent of $\mathrm{T}$ Cells in the murine model. To confirm the putative $T$ cell independent nature of the response in humans, we studied PnAb secretion by in vitro 1ymphoctye cultures. Twelve day culture supernatants of blood mononuclear cells drawn before and 1 and 3 weeks post-immunization with Pneumococcal Vaccine were assayed for total IgG and PnAb by ELISA. Maximum PnAb secretion occurred at 1 week post-immunization in both unstimulated (177 $\pm 90 \mathrm{ng} / \mathrm{ml}$ ) and pokeweed zation in both unstimulated $(177 \pm 90 \mathrm{ng} / \mathrm{ml})$ and pokeweed
stimulated $(300+200 \mathrm{ng} / \mathrm{ml})$ cultures. PnAb secretion was not due to polyclonal stimulation since no change in anti-tetanus toxoid secretion was found and a paradoxical decrease in total IgG secretion occurred (pre=2.4 mcg, I wh post $=1.3 \mathrm{mcg}, \mathrm{p}<$ (.001-10 $\mathrm{ng} / \mathrm{m} 1$ ) enriched $T$ cell depleted cultures had similar PnAb kinetics to unfractionated mononuclear cells: pre $=1.5+1.6$ ngAb/mcgIgG, $1 \mathrm{wk}$ post $=180+175 \mathrm{ngAB} / \mathrm{mcgIgG}, 3 \mathrm{wk}$ post $=381+380$

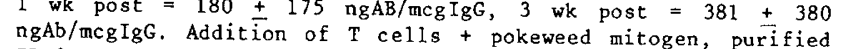
IL-2, or allogeneic $T$ helper factor from mixed lymphocyte culture supernatant had no effect on PnAb secretion expressed per mcg total IgG. These studies suggest that Pneumococcal Polysaccharide type 3 is a $T$ cell independent antigen in humans which may activate $B$ cells in a manner distinct from conven-
tional protein antigens.

\section{$\dagger 941$} PNEUMOCOCCAL TXPE 3 ANTIBODY IS RESTRICTED TO THE 1 IgG2 SUBCLASS. Douglas J. Barrett and E1ia M. ida College of Medicine, Gainesville.

To determine if human antibodies to Pneumococcal Polysaccharide type 3 are restricted in IgG subclass diversity, we tested sera from normal volunteers drawn before and after immunization $(n=9)$. Subclass-specific ELISA techniques using murine monoclonal antibodies to human IgG1, IgG3, IgG4 and the Ig fraction of sheep anti-IgG2 were developed. Enzyme-conjugated antibodies were shown to be specific by testing against homologous and non-homologous IgG subclasses in direct ELISA using WHO myeloma reference standards. The relative sensitivity of each subclass antibody conjugate differed as shown by reaction in competitive binding ELISA where $50 \%$ inhibition of binding for IgGl=0.1 mcg. IgG2 $=1.75 \mathrm{mcg}$, IgG3 $=0.25 \mathrm{mcg}$ and IgG4=0.175 mcg. End-point serum titer was defined as that dilution giving an optical density twice nonspecific background and was normalized to reflect the relative sensitivity of each subclass-specific assay. Preimmunization geometric mean titers of serum antibody were IgGl= 13.5, IgG2 $=258.7, \operatorname{IgG} 3=7.0$, and $\operatorname{IgG} 4=3.5$. Post-immunization titers were significantly higher for $\operatorname{IgG2}=955.0 \quad(p<.05)$ but unchanged for $\operatorname{IgGl}=20.8$, $\operatorname{IgG} 3=6.6$, and $\operatorname{IgG} 4=4.0$. Mean pre to post-immunization increases in antibody titer were significantly post-immunization
higher for $\operatorname{IgG2} 2=5.75(\mathrm{p}<0.05)$ compared to $\mathrm{IgG1}=1.55$, IgG3= higher for IgG2 2.75 ( $\mathrm{p}<0.05$ ) compared to $\mathrm{IgG1}=1.55$, IgG3=
1.0 , and $\mathrm{IgG4}=1.0$. These results demonstrate that $90-95 \%$ of human antibody to the putative $\mathrm{T}$-cell independent antigen Pneumococcal polysaccharide type 3 is restricted to the IgG2
subclass. 